\title{
The Role of Minimally Invasive Techniques in the Treatment of Thoracolumbar Trauma
}

\author{
Ankur S. Narain, ${ }^{1}$ Fady Y. Hijji, ${ }^{1}$ Kelly H. Yom, ${ }^{1}$ Krishna T. Kudaravalli, ${ }^{1}$ and Kern Singh ${ }^{1,}$ \\ ${ }^{1}$ Department of Orthopaedic Surgery, Rush University Medical Center, 1611 W. Harrison St Suite 300, Chicago, IL, 60612 \\ "Corresponding author: Kern Singh, MD, Professor, Department of Orthopaedic Surgery, Rush University Medical Center, 1611 W. Harrison St, Suite \#300, Chicago, IL 60612. Tel: \\ +312-4322373, Fax: +708-4095179, E-mail: kern.singh@rushortho.com
}

Received 2016 August 22; Revised 2016 August 31; Accepted 2016 September 22.

\begin{abstract}
Context: Thoracolumbar injuries are common manifestations of spinal trauma. While non-operative therapy is indicated in certain cases of isolated injury, operative therapy via open approaches are widely utilized. Recently, minimally invasive surgical (MIS) approaches have been adapted for the management of thoracolumbar trauma in an effort to avoid the operative morbidity of open thoracolumbar procedures.

Purpose: The purpose of this review is to perform a critical analysis of the literature regarding the clinical efficacy and safety of MIS procedures in the management of thoracolumbar trauma.

Evidence Acquisition: PubMed and MEDLINE databases were searched for articles published on the topic of MIS treatment of traumatic thoracolumbar injuries. Studies included in this review were comprised of clinical case series, retrospective cohort studies, non-randomized prospective cohort studies, prospective randomized controlled trials, and meta-analyses.

Results: The majority of published studies were retrospective clinical case series comprising level IV evidence. The majority of studies demonstrated the viability of MIS approaches as a treatment modality for thoracolumbar trauma in regards to clinical outcomes, radiographic outcomes, and complication rates. Additionally, MIS procedures were associated with reductions in operative time, intraoperative blood loss, and immediate postoperative pain.

Conclusions: MIS approaches to thoracolumbar trauma are viable treatment strategies in regards to clinical efficacy and safety. While the results for MIS procedures are promising, more high-quality prospective studies are necessary in order to make definitive conclusions regarding the superiority of MIS over open surgical strategies.
\end{abstract}

Keywords: Thoracolumbar Trauma, Spine Trauma, Operative Therapy, Minimally Invasive Surgery, Short-Segment Pedicle Screw Fixation, Percutaneous Kyphoplasty, Percutaneous Vertebroplasty, Thoracoscopic Surgery, Endoscopic Surgery, Lateral Approach

\section{Context}

Thoracolumbar injuries are common in the setting of trauma, with a reported annual incidence approaching 64 per 100,000 people in the United States (1). Of all trauma resulting in spinal injuries, involvement of the thoracolumbar region occurs in $72.5 \%-90 \%$ of cases $(1,2)$. These injuries are often a result of acceleration-deceleration forces, which commonly exist in motor vehicle accidents and falls $(2,3)$. The high-energy nature of these accelerationdeceleration injuries often leads to significant associated morbidity, with up to $30 \%$ of patients with thoracolumbar trauma also presenting with additional intraabdominal soft tissue or hollow viscus injury (4).

Management strategies for traumatic thoracolumbar injuries are dependent upon the type and severity of the presenting injury. While non-operative therapy with orthoses and casting is an option in cases of isolated injury with intact neurologic function (5-10), operative therapy is an increasingly popular strategy. This is especially true in cases involving burst fractures, translation/rotation fractures, distraction injuries, injuries with involvement of the posterior ligamentous complex, or injuries with associated neurologic deficits (11). Furthermore, operative therapy is frequently utilized in the setting of polytrauma or in instances where the patient cannot tolerate long-term orthoses and casting (10).

Historically, open procedures have been the mainstay of operative therapy for traumatic thoracolumbar injuries (12-14). Depending on the type and morphology of the injury, a variety of approaches can be utilized. The posterior approach involves pedicle screw fixation with or without vertebral body augmentation via vertebroplasty/kyphoplasty (12-14). On the other hand, the anterior approach allows for direct access to the vertebral body and spinal canal for reconstruction via interbody fusion or corpectomy (12-14). The anterior and posterior approaches can be jointly utilized in select cases. While many previous studies have demonstrated adequate outcomes after these procedures, the invasiveness of these approaches is associ- 
ated with significant operative morbidity and prolonged inpatient recovery times.

Minimally invasive surgical (MIS) techniques have been developed and utilized for spinal procedures. Various studies investigating the use of MIS techniques for elective spinal decompression and fusion have demonstrated decreases in intraoperative blood loss, postoperative pain, reduced time to ambulation, and shorter lengths of hospital stay when compared to conventional open surgery. MIS approaches have also been adapted for use in the setting of traumatic thoracolumbar injuries. In this context, the purpose of this review is to summarize and perform a critical analysis of the literature regarding the clinical efficacy and safety of MIS procedures in the management of traumatic thoracolumbar injuries.

\section{Evidence Acquisition}

A literature search was performed using the PubMed and MEDLINE databases to identify publications on the use of MIS techniques in the management of thoracolumbar trauma published by November 2016. Only articles published in English with full-text availability were used in this review. Additionally, hand checks of reference lists were performed to assure the adequacy of the literature included in this review.

Studies that were included in this review were comprised of clinical case series, retrospective cohort studies, non-randomized prospective cohort studies, prospective randomized controlled trials, and meta-analyses. Biomechanical studies, single case reports, and other reviews without a concomitant meta-analysis were excluded from this review. Studies that did not present clinical data or did not present clinical follow-up findings were also excluded from this review.

\section{Results}

\subsection{Percutaneous Pedicle Screw Fixation}

Percutaneous pedicle screw fixation (PPSI) has been utilized to provide immediate stabilization and adequate reduction in cases of thoracolumbar trauma (15-24). PPSI without anterior reconstruction or augmentation is primarily utilized in AO type A1 (wedge-compression) and A2 (split) fractures without posterior vertebral wall involvement or significant vertebral body comminution (25). While many clinical case series and retrospective studies have detailed the clinical and radiographic efficacy of PPSI, only a few studies have presented high-level evidence from prospective investigations. Jiang et al. undertook such a prospective, randomized controlled trial
(RCT) of 61 patients with single-level thoracolumbar burst fractures without neurologic deficit (20). In this study, 30 patients were randomized to a paraspinal fixation approach while 31 patients were randomized to fixation via PPSI. The patients treated percutaneously demonstrated significantly lower intraoperative blood loss and shorter operative times compared to the paraspinal approach. At3month follow-up, the percutaneous group had less pain as evidenced by lower visual analogue scale (VAS) pain scores and better functional recovery as evidenced by higher oswestry disability index (ODI) scores. Radiographically, however, the paraspinal approach demonstrated better kyphotic correction and restoration of vertebral height immediately after surgery, especially in patients without successful postural reduction from the procedure. Despite this, both groups had statistically similar long-term clinical outcomes at follow-up periods of greater than 1 year.

Lyu et al. performed a prospective RCT in which 90 patients with single-level thoracolumbar fractures without neurological deficits were treated with one of three fixation techniques: three-level percutaneous fixation (group A), two-level percutaneous fixation (group B), or three-level open fixation (group C) (21). The patient sample consisted of 30 patients randomized to one of the three groups. Groups receiving percutaneous fixation exhibited shorter operative times than the open fixation group, with the short-segment two-level percutaneous group having the shortest operative duration. In comparing the three-level percutaneous and open fixation groups, the percutaneous group had significantly reduced intraoperative blood loss and reduced postoperative pain at 3-month follow-up. At an average follow-up of 17.7 months, all groups demonstrated similar radiographic outcomes in terms of Cobb angle and anterior height ratio correction.

Grossbach et al. performed a prospective, nonrandomized study of 38 patients with flexion-distraction injury treated either with open fixation and fusion or PPSI (18). Similar to the findings exhibited by the previously mentioned studies, the PPSI group trended towards shorter operative times and had significantly lower average intraoperative blood loss. These findings were replicated by Vanek et al., who performed a prospective, non-randomized study of 35 patients with burst fractures treated either with open surgical fusion or PPSI (25). In addition, Vanek et al. also determined that postoperative VAS pain scores over the first 7 postoperative days were lower in the PPSI group. Long-term follow-up at 2 years postoperatively demonstrated that patient satisfaction rates were similar in the open and PPSI groups.

Complications after PPSI have also been a topic of study within the literature, with a reported incidence in up to $12 \%$ of cases $(15,17,18,20-23)$. The most commonly reported 
complications involve screw misplacement, screw loosening, and subsequent removal of instrumentation. In regards to instrumentation, the previously mentioned study by Jiang et al. noted that paraspinal and PPSI approaches had statistically similar rates of screw misplacement (20). Vanek et al. demonstrated similar findings, while also noting that the majority of cases of screw misplacement were clinically asymptomatic (25). In regards to medical and neurologic complications, isolated incidences of complications such as wound infection and cauda equina syndrome have been described in the literature. Gasbarrini et al. reported 1 case of cauda equina syndrome, 1 case of wound infection, and 1 case of non-union in a cohort of 101 patients treated with PPSI for thoracolumbar fractures (17). Cappucio et al. provided the most comprehensive evaluation of complications after PPSI in a study of 99 patients treated for 176 vertebral fractures (15). In this cohort, medical and neurologic complications included 1 case of cauda equina syndrome requiring urgent surgical revision, 1 case of wound infection with dehiscence that required surgical debridement with implant removal, and 1 case of nonunion which required anterior thoracoscopic fusion.

\subsection{Percutaneous Vertebral Augmentation}

While short-segment pedicle screw instrumentation (SSPI) remains the most utilized treatment modality for thoracolumbar trauma, concerns exist over its efficacy in the setting of injuries with anterior column instability and comminution (26-28). In these cases, pedicle screw fixation alone may not provide adequate anterior support and points of fixation (27). In these instances, treatment strategies combining percutaneous vertebroplasty/kyphoplasty along with short-segment pedicle screw fixation have been developed.

While many studies have described the efficacy of this combined approach (26-36), the majority of publications consist of level IV evidence from clinical case series. In terms of clinical outcomes, Zairi et al. assessed 41 patients with single-level thoracolumbar fractures and determined that percutaneous kyphoplasty and short-segment pedicle screw instrumentation led to significant improvements in pain at 15 months postoperatively (36). Radiographically, parameters including vertebral kyphosis, local kyphosis, and percentage of vertebral body collapse were all significantly improved at last follow-up. Koroveiss et al. demonstrated similar clinical and radiographic findings in a population of 18 patients undergoing percutaneous kyphoplasty and SSPI for single-level burst or compression fractures (27). The authors also determined that all patients had significant improvement in physical and neurologic function, with all participants demonstrating normal sen- sory and motor capabilities based on the American spinal injury association (ASIA) scale postoperatively.

The use of percutaneous vertebroplasty and kyphoplasty, with or without short-segment pedicle screw instrumentation, is not devoid of complications. The most commonly reported complication is cement extrusion, which in serious cases can lead to spinal cord compression or pulmonary embolism. In the studies included in this review, the rate of cement leakage ranged from $11.1 \%$ - 96.2\% (2636). However, in the vast majority of cases the leakages were determined to be asymptomatic and required no further intervention. Symptomatic cement leakages were described by Chen et al., who noted 1 case of cement embolism that produced a mild cough without dyspnea that eventually self-resolved (32). Rahamimov et al., in a cohort of 40 patients undergoing treatment for thoracolumbar burst fractures, described 3 cases of cement emboli to the pulmonary artery via the inferior vena cava and segmental veins (34).

Novel methods of vertebral augmentation involving the implantation of intracorporeal devices have been a recent topic of interest within the literature $(37,38)$. Intracorporeal devices have the proposed advantage of preventing leakage-associated complications due to the minimization of cement introduced into the vertebral body. Furthermore, the internal structural support provided by these devices has also been proposed to prevent long-term loss of vertebral body height correction. Ender et al., in a study of 15 patients with incomplete burst fractures, demonstrated that implantation of cement-augmented titanium mesh cages led to improvements in VAS pain scores, ODI scores, and kyphotic angle at 12 months postoperatively (38). Most importantly, the authors noted that no cementrelated complications occurred in their series. Takami et al. performed a similar study, utilizing vertebral augmentation via hydroxyapatite blocks in 21 patients with thoracolumbar burst fractures (37). Similar improvements in pain scores and radiographic kyphotic angles were demonstrated. Anterior vertebral body height was also significantly restored, with no significant loss of correction at a mean follow-up of 21.9 months. While these novel methods have demonstrated promising early outcomes, more investigation is required to determine their true efficacy.

\subsection{Anterior Reconstruction with Thoracoscopic/Endoscopic or Extreme Lateral Approaches}

Anterior approaches involving vertebral body reconstruction are indicated in cases of combined anterior and posterior injury, or in instances where spinal column injury presents with concurrent neurologic deficits (39-47). Anterior approaches allow for direct visualization of the anterior spinal column with direct access to the spinal 
canal. Minimally invasive anterior approaches, such as those involving endoscopy or thoracoscopy, are proposed to prevent the high morbidity typically associated with open anterior approaches. Kim et al. described a case series of 212 patients with unstable thoracolumbar fractures with or without neurologic deficits (41). The surgical approach used in this study was a four-portal thoracoscopic, transdiaphragmatic anterior reconstruction with possible posterior pedicle screw instrumentation. Anterior reconstruction was performed with lateral plating and either local bone graft or expandable cages. Postoperatively, $34 \%$ of patients with neurologic deficits improved according to Frankel grade, with no occurrence of new deficits. At 1-year follow-up, radiographic fusion was observed in $85 \%$ - $90 \%$ of cases. The overall complication rate was $11.7 \%$, with an approach-related complication rate of 5.6\%. Approach-related complications included pleural effusion, pneumothorax, intercostal neuralgia, and transient L1 sensory deficit.

Ringel et al. performed a similar study in 83 patients with unstable thoracolumbar fracture managed with 3 4 portal thoracoscopic/endoscopic techniques (44). Anterior reconstruction consisted of monosegmental interbody fusion, partial corpectomy, or complete vertebral body replacement depending on the clinical indication of the procedure. Clinically, $19 \%$ of patients with injuryrelated neurologic deficit improved postoperatively. Average postoperative kyphotic correction was $9^{\circ}$, with a $6^{\circ}$ loss of correction at an average follow-up of 23 months. At last follow-up, fusion rates were $87 \%$. In regards to complications, the conversion rate to open procedures was $6 \%$. $3.6 \%$ of patients experienced approach-related complications, including insufficient pulmonary function, pleural empyema, and one case of extended ventilation.

Mini-open and MIS lateral approaches, originally developed for the elective management of degenerative pathologies, are also being increasingly utilized for anterior column reconstruction in cases of thoracolumbar trauma. Similar to endoscopic/thoracoscopic approaches, the proposed advantages of lateral approaches stem from their decreased invasiveness compared to conventional open procedures. Smith et al. performed one of the earliest investigations of a mini-open lateral approach in a cohort of 52 patients with acute, traumatic, unstable thoracolumbar fractures (46). Patients underwent lateral corpectomy with implantation of an expandable titanium cage and either supplemental anterior or posterior fixation. Postoperatively, neurologic impairment as measured by ASIA scores was improved at 24-month follow-up. Additionally, no cases of neurologic deterioration were encountered. The complication rate was $15.4 \%$, with reported complications including incidental durotomy, intercostal neural- gia, deep vein thrombosis, pleural effusion, and superficial posterior infection. Mild cage subsidence was seen in 13.5\% of patients; however, only 1 patient developed pain which required a revision procedure.

Li et al. also reported on the utilization of an MIS lateral approach, with an additional comparison to an open approach cohort (42). 30 patients with three-column thoracolumbar fractures and subsequent neurologic deficits were managed; 12 via MIS lateral lumbar interbody fusion (LLIF) and 18 via the traditional open procedure. Patients in the MIS LLIF cohort had significantly lower operative times and intraoperative blood loss, while both cohorts demonstrated statistically similar improvements in neurologic function postoperatively. At an average follow-up of 12.75 14.8 months, both groups had equivalent radiographic outcomes as evidenced by Cobb angle correction. The MIS LLIF cohort also had a decreased overall complication rate $(8.3 \%$ vs. $33 \%$ ) and decreased major complication rate compared to the open cohort, but this result did not reach statistical significance.

\section{Conclusions}

Spinal injuries are common in the setting of trauma, with thoracolumbar injuries representing the majority of cases $(1,2)$. In cases where surgical management is required, traditional open procedures are still widely used. However, a variety of minimally invasive approaches have been adapted to traumatic settings with the intention of reducing the operative morbidity associated with conventional techniques. The purpose of this review was to critically summarize the literature regarding the utilization of MIS approaches in managing thoracolumbar spinal trauma.

Review of the current literature suggests that minimally invasive approaches are an effective and viable strategy in the treatment of thoracolumbar trauma. The reviewed literature is consistent in demonstrating that MIS approaches are associated with reduced operative times, reduced intraoperative blood loss, and improvement in the level of immediate postoperative pain. In regards to long-term outcomes, the majority of reviewed studies demonstrate that MIS approaches offer significant postoperative pain reduction, disability improvement, and restoration of radiographic alignment parameters. Complication rates as presented in the reviewed studies are also acceptable. In MIS approaches, however, special concern must be paid to approach-specific complications such as cement leakage in percutaneous vertebroplasty/kyphoplasty (26-36), pulmonary complications in thoracoscopic/endoscopic approaches (41, 45, 46), and psoas muscle pathology in lateral approaches $(39,42,47)$. 
Table 1. Summary of Select Studies for Various MIS Modalities Utilized for the Management of Thoracolumbar Trauma

\begin{tabular}{|c|c|c|c|c|c|c|}
\hline Author & Year & $\begin{array}{l}\text { Evidence } \\
\text { Level }\end{array}$ & Operative Modality & Sample Size (n) & $\begin{array}{l}\text { Follow-Up, } \\
\text { Mo }\end{array}$ & Primary Findings \\
\hline \multirow{2}{*}{ Jiang et al. } & \multirow{2}{*}{2012} & \multirow{2}{*}{ I } & \multirow{2}{*}{ PPSI, Paraspinal } & \multirow{2}{*}{31 PPSI 30, Paraspinal } & \multirow{2}{*}{$58.3-59.0$} & $\begin{array}{l}\text { Percutaneous treatment had shorter operative time, less } \\
\text { intraoperative blood loss, better pain and disability scores at } \\
\text { 3-months postoperatively }\end{array}$ \\
\hline & & & & & & $\begin{array}{l}\text { Paraspinal approach had better kyphotic correction and } \\
\text { restoration of vertebral height }\end{array}$ \\
\hline Lyu et al. & 2016 & I & PPI, Open Fixation & 60 PPSI, 30 Open & 17.7 & $\begin{array}{l}\text { Percutaneous groups had shorter operative times, reduced } \\
\text { intraoperative blood loss, reduced pain }\end{array}$ \\
\hline Grossbach et al. & 2013 & II & PPSI, Open fixation & 11 PPSI, 27 Open & $9.0-18.5$ & $\begin{array}{l}\text { Trend towards shorter operative time and lower average } \\
\text { intraoperative blood loss in PPSI group }\end{array}$ \\
\hline \multirow{2}{*}{ Vanek et al. } & \multirow{2}{*}{2014} & \multirow{2}{*}{ II } & \multirow{2}{*}{ PPSI, Open fixation } & \multirow{2}{*}{18 PPSI, 19 Open } & \multirow{2}{*}{24.0} & Lower postoperative VAS scores at 7 days in PPSI group \\
\hline & & & & & & Similar patient satisfaction rate between groups \\
\hline \multirow{2}{*}{ Zairi et al. } & \multirow{2}{*}{2014} & \multirow{2}{*}{ IV } & \multirow{2}{*}{ Percutaneous KP and PPSI } & \multirow{2}{*}{41} & \multirow{2}{*}{15.0} & Significant improvements in postoperative pain \\
\hline & & & & & & Significant improvement in radiographic alignment parameters \\
\hline \multirow{2}{*}{ Kim et al. } & \multirow{2}{*}{2004} & \multirow{2}{*}{ IV } & \multirow{2}{*}{ Thoracoscopic, Reconstruction } & \multirow{2}{*}{212} & \multirow{2}{*}{46.8} & $\begin{array}{l}34 \% \text { of patients with neurologic deficits improved } \\
\text { postoperatively }\end{array}$ \\
\hline & & & & & & Fusion observed in $85 \%$ - $90 \%$ of cases \\
\hline \multirow{3}{*}{ Ringel et al. } & \multirow{3}{*}{2008} & \multirow{3}{*}{ IV } & \multirow{3}{*}{$\begin{array}{l}\text { Thoracoscopic/Endoscopic, } \\
\text { Reconstruction }\end{array}$} & \multirow{3}{*}{83} & \multirow{3}{*}{23.0} & $19 \%$ of patients with neurologic deficits improved postoperatively \\
\hline & & & & & & Average kyphotic correction $9^{\circ}, 6^{\circ}$ loss of correction \\
\hline & & & & & & Fusion rate $87 \%$ \\
\hline Smith et al. & 2010 & IV & Lateral Reconstruction & 52 & 24.0 & $\begin{array}{l}\text { Neurologic impairment improved, no additional cases of } \\
\text { neurologic deterioration }\end{array}$ \\
\hline Iiot & Oot & $\pi$ & Lateral Reconstruction, Open & 19 heto & 7270 & Lateral cohort had reduced operative time and blood loss \\
\hline Liet di. & 2013 & ${ }^{11}$ & Reconstruction & 12 Idterdi, 18 Opent & $12.7-14.8$ & $\begin{array}{l}\text { Similar improvements in neurologic function and Cobb angle } \\
\text { correction in both groups }\end{array}$ \\
\hline
\end{tabular}

Abbreviations: KP, Kyphoplasty; PPSI, Percutaneous Pedicle Screw Instrumentation.

Indications for the utilization of particular MIS procedures are based primarily on injury morphology and the presence of associated neurologic deficits. Furthermore, indications and patterns of utilization are also driven by the types of cases described in large case series and prospective clinical trials. In these studies, indications are often presented in the context of the AO thoracolumbar spine injury classification system (48). As evidenced by the reviewed literature, indications for percutaneous pedicle screw fixation include AO type A1 (wedge-compression) and type A2 (split) fractures without involvement of the posterior vertebral wall or significant comminution. Furthermore, additional criteria include spinal canal narrowing less than 50\% and angular kyphosis greater than $15^{\circ}$ (24). Vertebral augmentation via percutaneous vertebroplasty/kyphoplasty is combined with PPSI in cases displaying significant anterior instability or marked vertebral body comminution. For MIS anterior reconstructive techniques, morphological indications include anterior-only AO type A fractures, along with AO type B distraction and type $C$ translational injuries that involve the anterior and posterior vertebral elements. Furthermore, injury of any morphologic type presenting with neurologic deficits is typically an indication for MIS anterior reconstruction. In these cases, reconstructive approaches aid in spinal canal decompression by allowing for improved access to the anterior vertebral elements and spinal canal.

One barrier to more widespread adoption of MIS procedures for the treatment of thoracolumbar trauma is the learning curve, which is perceived to be associated with increased morbidity and reduced efficacy during the initial cases in a surgeon's practice. Few studies have been developed to examine the learning curve in trauma-specific populations; however, evidence from the literature regarding populations with degenerative or mixed pathology are still valuable $(49,50)$. These studies have indicated that the initial period of cases comprising the learning curve of MIS approaches is safe. $\mathrm{Ng}$ et al., in a study of the first $32 \mathrm{pa-}$ tients in their practice undergoing fusion via a minimallyinvasive lateral approach, demonstrated a significant reduction in operative time after the $22^{\text {nd }}$ case (50). However, the authors demonstrated that early and late cases had no significant differences in radiation exposure, length of stay, postoperative narcotic usage, and overall clinical out- 
comes. Similarly, Al-Sayyad et al., in a study of the first 70 patients undergoing thoracoscopic spine surgery in their practice, noted the incidence of only 3 approach-related complications with no long-term consequences (49). Furthermore, patient satisfaction rates were high over this initial period of cases, with $71 \%$ of patients reporting they would have the procedure performed again if necessary. In the context of MIS management of thoracolumbar trauma, further research is necessary to assess the learning curve in trauma-specific populations rather than the mixed populations included in the aforementioned studies.

Another barrier to adoption of MIS procedures is the lack of high-quality, prospective, level I and II studies on the topic. The majority of studies identified for inclusion in this review consisted of retrospective case series and other level IV evidence. This is especially true in regards to newer techniques such as endoscopic/thoracoscopic spinal surgery and lateral access approaches. While these case series provide valuable data points, conduct of more prospective RCTs on the topic of MIS treatment of thoracolumbar trauma is necessary to provide the greatest opportunity to meaningfully influence clinical practice patterns.

This review is not without limitations. First, biomechanical and cadaveric studies were not included in this analysis. While these studies represent a significant portion of the literature regarding MIS approaches, the focus of this review was clinical and radiographic findings in surgically treated patients. Second, there were differing practices within each study regarding the timing of surgery and the staging of anterior-posterior procedures. These differences limit the ability to compare studies, even those regarding the same surgical approaches. Similarly, there were differing criteria in each study regarding followup periods, clinical parameters, radiographic parameters, and patient-reported outcome measures utilized. While these limitations may hinder the comparative ability of this review, they are not unique to this investigation and are an aspect of all literature reviews.

This review suggests that MIS approaches to thoracolumbar trauma are a viable treatment modality in the context of improved clinical outcomes, adequate deformity correction, and acceptable complication profiles. Indications for certain MIS techniques are based on the morphological characteristics of the injury along with the presence or absence of neurologic deficits. While percutaneous pedicle screw fixation and vertebroplasty/kyphoplasty can be utilized for injuries involving the anterior column, anterior reconstruction is necessary for injuries involving combined anterior-posterior column injury or those injuries with neurologic deficits. Significant barriers to the adoption of MIS techniques include the learning curve and relative lack of high-level prospective studies on the topic. More level I and II studies investigating the efficacy of MIS approaches in traumatic settings are necessary to increase the utilization of these approaches.

\section{Footnote}

Financial Disclosure: No funds were received in support of this work. No benefits in any form have been or will be received from any commercial party related directly or indirectly to the subject of this manuscript.

\section{References}

1. Hu R, Mustard CA, Burns C. Epidemiology of incident spinal fracture in a complete population. Spine (Phila Pa 1976). 1996;21(4):492-9. doi: 10.1097/00007632-199602150-00016. [PubMed: 8658254].

2. Ghobrial GM, Jallo J. Thoracolumbar spine trauma: review of the evidence. J Neurosurg Sci. 2013;57(2):115-22. [PubMed: 23676860].

3. Denis F. The three column spine and its significance in the classification of acute thoracolumbar spinal injuries. Spine (Phila Pa 1976). 1983;8(8):817-31. doi: 10.1097/00007632-198311000-00003. [PubMed: 6670016].

4. Chapman JR, Agel J, Jurkovich GJ, Bellabarba C. Thoracolumbar flexion-distraction injuries: associated morbidity and neurological outcomes. Spine (Phila Pa 1976). 2008;33(6):648-57. doi: 10.1097/BRS.0b013e318166df7b. [PubMed: 18344859].

5. Cantor JB, Lebwohl NH, Garvey T, Eismont FJ. Nonoperative management of stable thoracolumbar burst fractures with early ambulation and bracing. Spine (Phila Pa 1976). 1993;18(8):971-6. doi: 10.1097/00007632-199306150-00004. [PubMed: 8367784].

6. Gnanenthiran SR, Adie S, Harris IA. Nonoperative versus operative treatment for thoracolumbar burst fractures without neurologic deficit: a meta-analysis. Clin Orthop Relat Res. 2012;470(2):567-77. doi 10.1007/s11999-011-2157-7. [PubMed: 22057820].

7. Mumford J, Weinstein JN, Spratt KF, Goel VK. Thoracolumbar burst fractures. The clinical efficacy and outcome of nonoperative management. Spine (Phila Pa 1976). 1993;18(8):955-70. doi: 10.1097/00007632199306150-00003. [PubMed: 8367783].

8. Shen WJ, Shen YS. Nonsurgical treatment of three-column thoracolumbar junction burst fractures without neurologic deficit. Spine (Phila Pa 1976). 1999;24(4):412-5. doi: 10.1097/00007632-19990215000024. [PubMed: 10065527].

9. Weinstein JN, Collalto P, Lehmann TR. Thoracolumbar "burst" fractures treated conservatively: a long-term follow-up. Spine (Phila Pa 1976). 1988,13(1):33-8. doi: 10.1097/00007632-198801000-00008. [PubMed: 3381135].

10. Wood KB, Buttermann GR, Phukan R, Harrod CC, Mehbod A, Shannon $\mathrm{B}$, et al. Operative compared with nonoperative treatment of a thoracolumbar burst fracture without neurological deficit: a prospective randomized study with follow-up at sixteen to twenty-two years. $J$ Bone Joint Surg Am. 2015;97(1):3-9. doi: 10.2106/JBJS.N.00226. [PubMed: 25568388].

11. Lee JY, Vaccaro AR, Lim MR, Oner FC, Hulbert RJ, Hedlund R, et al. Thoracolumbar injury classification and severity score: a new paradigm for the treatment of thoracolumbar spine trauma. J Orthop Sci. 2005;10(6):671-5. doi: 10.1007/s00776-005-0956-y. [PubMed: 16307197]. 
12. Dai LY, Jiang SD, Wang XY, Jiang LS. A review of the management of thoracolumbar burst fractures. Surg Neurol. 2007;67(3):221-31. doi: 10.1016/j.surneu.2006.08.081. [PubMed: 17320622] discussion 231.

13. Verlaan JJ, Diekerhof CH, Buskens E, van der Tweel I, Verbout AJ, Dhert WJ, et al. Surgical treatment of traumatic fractures of the thoracic and lumbar spine: a systematic review of the literature on techniques, complications, and outcome. Spine (Phila Pa 1976). 2004;29(7):803-14. doi:10.1097/01.BRS.0000116990.31984.A9. [PubMed:15087804].

14. Chipman JG, Deuser WE, Beilman GJ. Early surgery for thoracolumbar spine injuries decreases complications. JTrauma. 2004;56(1):52-7. doi: 10.1097/01.TA.0000108630.34225.85. [PubMed: 14749565].

15. Cappuccio M, Amendola L, Paderni S, Bosco G, Scimeca G, Mirabile L, et al. Complications in minimally invasive percutaneous fixation of thoracic and lumbar spine fractures. Orthopedics. 2013;36(6):e729-34. doi: 10.3928/01477447-20130523-16. [PubMed: 23746033].

16. Fitschen-Oestern S, Scheuerlein F, Weuster M, Klueter T, Menzdorf L, Varoga D, et al. Reduction and retention of thoracolumbar fractures by minimally invasive stabilisation versus open posterior instrumentation. Injury. 2015;46 Suppl 4:S63-70. doi: 10.1016/S00201383(15)30020-6. [PubMed: 26542868].

17. Gasbarrini A, Cappuccio M, Colangeli S, Posadas MD, Ghermandi R, Amendola L. Complications in minimally invasive percutaneous fixation of thoracic and lumbar spine fractures and tumors. Eur Spine J. 2013;22 Suppl 6:S965-71. doi: 10.1007/s00586-013-3019-7. [PubMed: 24057199].

18. Grossbach AJ, Dahdaleh NS, Abel TJ, Woods GD, Dlouhy BJ, Hitchon PW. Flexion-distraction injuries of the thoracolumbar spine: open fusion versus percutaneous pedicle screw fixation. Neurosurg Focus. 2013;35(2):E2. doi: 10.3171/2013.6.FOCUS13176. [PubMed: 23905953].

19. Heintel TM, Berglehner A, Meffert R. Accuracy of percutaneous pedicle screws for thoracic and lumbar spine fractures: a prospective trial. Eur Spine J. 2013;22(3):495-502. doi: 10.1007/s00586-012-2476-8. [PubMed: 22903200].

20. Jiang XZ, Tian W, Liu B, Li Q, Zhang GL, Hu L, et al. Comparison of a paraspinal approach with a percutaneous approach in the treatment of thoracolumbar burst fractures with posterior ligamentous complex injury: a prospective randomized controlled trial. J Int Med Res. 2012;40(4):1343-56. doi: 10.1177/147323001204000413. [PubMed: 22971486].

21. Lyu J, Chen K, Tang Z, Chen Y, Li M, Zhang Q. A comparison of three different surgical procedures in the treatment of type A thoracolumbar fractures: a randomized controlled trial. Int Orthop. 2016;40(6):12338. doi: 10.1007/s00264-016-3129-z. [PubMed: 26907876].

22. Ni WF, Huang YX, Chi YL, Xu HZ, Lin Y, Wang XY, et al. Percutaneous pedicle screw fixation for neurologic intact thoracolumbar burst fractures. J Spinal Disord Tech. 2010;23(8):530-7. doi: 10.1097/BSD.ob013e3181c72d4c. [PubMed: 21131801].

23. Palmisani M, Gasbarrini A, Brodano GB, De Iure F, Cappuccio M, Boriani L, et al. Minimally invasive percutaneous fixation in the treatment of thoracic and lumbar spine fractures. EurSpine J. 2009;18 Suppl 1:714. doi: 10.1007/s00586-009-0989-6. [PubMed: 19399533].

24. Wild MH, Glees M, Plieschnegger C, Wenda K. Five-year follow-up examination after purely minimally invasive posterior stabilization of thoracolumbar fractures: a comparison of minimally invasive percutaneously and conventionally open treated patients. Arch Orthop Trauma Surg. 2007;127(5):335-43. doi: 10.1007/s00402-006-02649. [PubMed: 17165033].

25. Vanek P, Bradac O, Konopkova R, de Lacy P, Lacman J, Benes V. Treatment of thoracolumbar trauma by short-segment percutaneous transpedicular screw instrumentation: prospective comparative study with a minimum 2-year follow-up. J Neurosurg Spine. 2014;20(2):150-6. doi: 10.3171/2013.11.SPINE13479. [PubMed: 24358996].

26. Gu Y, Zhang F, Jiang X, Jia L, McGuire R. Minimally invasive pedicle screw fixation combined with percutaneous vertebroplasty in the surgical treatment of thoracolumbar osteoporosis fracture. J Neurosurg Spine. 2013;18(6):634-40. doi:10.3171/2013.3.SPINE12827. [PubMed:
23560713].

27. Korovessis P, Hadjipavlou A, Repantis T. Minimal invasive short posterior instrumentation plus balloon kyphoplasty with calcium phosphate for burst and severe compression lumbar fractures. Spine (Phila Pa 1976). 2008;33(6):658-67. doi: 10.1097/BRS.ob013e318166eobb. [PubMed: 18344860].

28. Zairi F, Aboukais R, Marinho P, Allaoui M, Assaker R. Minimally invasive percutaneous stabilization plus balloon kyphoplasty for the treatment of type A thoraco lumbar spine fractures: minimum 4 year's follow-up. J Neurosurg Sci. 2014;58(3):169-75. [PubMed: 25033976].

29. Bironneau A, Bouquet C, Millet-Barbe B, Leclercq N, Pries P, Gayet LE. Percutaneous internal fixation combined with kyphoplasty for neurologically intact thoracolumbar fractures: a prospective cohort study of 24 patients with one year of follow-up. Orthop Traumatol Surg Res. 2011;97(4):389-95. doi: 10.1016/j.otsr.2011.02.009. [PubMed: 21546332].

30. Blondel B, Fuentes S, Pech-Gourg G, Adetchessi T, Tropiano P, Dufour $\mathrm{H}$. Percutaneous management of thoracolumbar burst fractures: Evolution of techniques and strategy. Orthop Traumatol Surg Res. 2011;97(5):527-32. doi: 10.1016/j.otsr.2011.03.020. [PubMed: 21763230].

31. Chen LH, Niu CC, Yu SW, Fu TS, Lai PL, Chen WJ. Minimally invasive treatment of osteoporotic vertebral compression fracture. Chang Gung Med J. 2004;27(4):261-7. [PubMed: 15239192].

32. Druschel C, Schaser KD, Rohlmann A, Pirvu T, Disch AC. Prospective quantitative assessment of spinal range of motion before and after minimally invasive surgical treatment of vertebral body fractures. Arch Orthop Trauma Surg. 2014;134(8):1083-91. doi:10.1007/s00402-0142035-3. [PubMed: 24974277].

33. Fuentes S, Blondel B, Metellus P, Gaudart J, Adetchessi T, Dufour H. Percutaneous kyphoplasty and pedicle screw fixation for the management of thoraco-lumbar burst fractures. Eur Spine J. 2010;19(8):1281-7. doi: 10.1007/s00586-010-1444-4. [PubMed: 20496038].

34. Rahamimov N, Mulla H, Shani A, Freiman S. Percutaneous augmented instrumentation of unstable thoracolumbar burst fractures. Eur Spine J. 2012;21(5):850-4. doi: 10.1007/s00586-011-2106-x. [PubMed: 22160173].

35. Teyssedou S, Saget M, Prebet R, Leclercq N, Vendeuvre T, Pries $\mathrm{P}$. Evaluation of percutaneous surgery in the treatment of thoracolumbar fractures. Preliminary results of a prospective study on 65 patients. Orthop Traumatol Surg Res. 2012;98(1):39-47. doi: 10.1016/j.otsr.2011.08.009. [PubMed: 22210506].

36. Zairi F, Court C, Tropiano P, Charles YP, Tonetti J, Fuentes S, et al. Minimally invasive management of thoraco-lumbar fractures: combined percutaneous fixation and balloon kyphoplasty. Orthop Traumatol Surg Res. 2012;98(6 Suppl):S105-11. doi: 10.1016/j.otsr.2012.06.004. [PubMed: 22901522].

37. Takami M, Yamada H, Nohda K, Yoshida M. A minimally invasive surgery combining temporary percutaneous pedicle screw fixation without fusion and vertebroplasty with transpedicular intracorporeal hydroxyapatite blocks grafting for fresh thoracolumbar burst fractures: prospective study. Eur J Orthop Surg Traumatol. 2014;24 Suppl 1:S159-65. doi: 10.1007/s00590-013-1266-2. [PubMed: 23828560].

38. Ender SA, Eschler A, Ender M, Merk HR, Kayser R. Fracture care using percutaneously applied titanium mesh cages (OsseoFix(R)) for unstable osteoporotic thoracolumbar burst fractures is able to reduce cement-associated complications-results after 12 months. J Orthop Surg Res. 2015;10:175. doi: 10.1186/s13018-015-0322-5. [PubMed: 26568074].

39. Gandhoke GS, Tempel ZJ, Bonfield CM, Madhok R, Okonkwo DO, Kanter AS. Technical nuances of the minimally invasive extreme lateral approach to treat thoracolumbar burst fractures. Eur Spine J. 2015;24 Suppl 3:353-60. doi: 10.1007/s00586-015-3880-7. [PubMed: 25801744].

40. Khan SN, Cha T, Hoskins JA, Pelton M, Singh K. Minimally invasive thoracolumbar corpectomy and reconstruction. Orthope- 
dics. 2012;35(1):e74-9. doi: 10.3928/01477447-20111122-04. [PubMed: 22229618].

41. Kim DH, Jahng TA, Balabhadra RS, Potulski M, Beisse R. Thoracoscopic transdiaphragmatic approach to thoracolumbar junction fractures. Spine J. 2004;4(3):317-28. doi: 10.1016/j.spinee.2003.11.007. [PubMed: 15125857].

42. Li X, Zhang J, Tang H, Lu Z, Liu S, Chen S, et al. Comparison Between Posterior Short-segment Instrumentation Combined With Lateral-approach Interbody Fusion and Traditional Wide-open Anterior-Posterior Surgery for the Treatment of Thoracolumbar Fractures. Medicine (Baltimore). 2015;94(44):e1946. doi: 10.1097/MD.0000000000001946. [PubMed: 26554800].

43. Pesenti S, Graillon T, Mansouri N, Rakotozanani P, Blondel B, Fuentes S. Minimal Invasive Circumferential Management of Thoracolumbar Spine Fractures. Biomed Res Int. 2015;2015:639542. doi: 10.1155/2015/639542. [PubMed: 26649311].

44. Ringel F, Stoffel M, Stuer C, Totzek S, Meyer B. Endoscopyassisted approaches for anterior column reconstruction after pedicle screw fixation of acute traumatic thoracic and lumbar fractures. Neurosurgery. 2008;62(5 Suppl 2):ONS445-52. doi: 10.1227/01.neu.0000326033.69961.c1. [PubMed: 18596528] discussion ONS452-3.

45. Schultheiss M, Kinzl L, Claes L, Wilke HJ, Hartwig E. Minimally invasive ventral spondylodesis for thoracolumbar fracture treatment: surgical technique and first clinical outcome. Eur Spine J. 2003;12(6):618-
24. doi: 10.1007/s00586-003-0564-5. [PubMed: 12898350].

46. Smith WD, Dakwar E, Le TV, Christian G, Serrano S, Uribe JS. Minimally invasive surgery for traumatic spinal pathologies: a mini-open, lateral approach in the thoracic and lumbar spine. Spine (Phila Pa 1976). 2010;35(26 Suppl):S338-46. doi: 10.1097/BRS.0b013e3182023113. [PubMed: 21160398].

47. Theologis AA, Tabaraee E, Toogood P, Kennedy A, Birk H, McClellan RT, et al. Anterior corpectomy via the mini-open, extreme lateral, transpsoas approach combined with short-segment posterior fixation for single-level traumatic lumbar burst fractures: analysis of health-related quality of life outcomes and patient satisfaction.J Neurosurg Spine. 2016;24(1):60-8. doi: 10.3171/2015.4.SPINE14944. [PubMed: 26431072].

48. Vaccaro AR, Oner C, Kepler CK, Dvorak M, Schnake K, Bellabarba C, et al. AOSpine thoracolumbar spine injury classification system: fracture description, neurological status, and key modifiers. Spine (Phila Pa 1976). 2013;38(23):2028-37. doi: 10.1097/BRS.0b013e3182a8a381. [PubMed: 23970107].

49. Al-Sayyad MJ, Crawford AH, Wolf RK. Early experiences with videoassisted thoracoscopic surgery: our first 70 cases. Spine (Phila Pa 1976). 2004;29(17):1945-51. [PubMed: 15534421] discussion 1952.

50. Ng CL, Pang BC, Medina PJ, Tan KA, Dahshaini S, Liu LZ. The learning curve of lateral access lumbar interbody fusion in an Asian population: a prospective study. Eur Spine J. 2015;24 Suppl 3:361-8. doi: 10.1007/s00586-015-3876-3. [PubMed: 25824482]. 